\title{
Blame, Control, or Responsibility? Validation of Sexual Assault Culpability Measures
}

Dr Sofia Persson ${ }^{1}$ (s.persson@leedsbeckett.ac.uk)

Dr Katie Dhingra ${ }^{1}$ (k.j.dhingra@leedsbeckett.ac.uk)

${ }^{1}$ Leeds Beckett University

RUNNING HEAD: VALIDATION OF SEXUAL ASSAULT CULPABILITY MEASURES

Address for correspondence:

Dr Sofia Persson

School of Social Sciences

Calverly Building

Portland Street

Leeds

LS1 3HE

s.persson@leedsbeckett.ac.uk

Author Note.

There is no conflict of interest to report.

The data used in this report forms part of a larger, previously published, research project:

Persson, S., \& Dhingra, K. (2021). Moderating Factors in Culpability Ratings and Rape Proclivity in Stranger and Acquaintance Rape: Validation of Rape Vignettes in a Community Sample. Journal of Interpersonal Violence. https://doi.org/10.1177/0886260521991294 


\begin{abstract}
Sexual assault research would benefit from a self-report measure that assesses the extent to which perpetrators and victims are perceived to be culpable for the occurrence of a rape. The goal of this study, therefore, was to validate new measures devised to capture the key facets of victim and perpetrator culpability - blame, control, and responsibility. Psychometric and descriptive properties of the new scales were examined in a sample of UK community participants assessed online $(N=255)$. Confirmatory factor analysis (CFA) was conducted using the lavaan package in the statistical software environment R. Both of the final scales demonstrated good validity and reliability. Specifically, internal consistencies for all subscales ranged from acceptable to excellent; CFA supported the hypothesised 3-factor scale structures; and, items exhibited good factor loadings onto respective subscales for both victim $(n=11)$ and perpetrator $(n=10)$ culpability. The culpability measures will likely be of use to researchers interested in a detailed, reliable, and valid assessment of victim and perpetrator culpability.
\end{abstract}

Key Words: Sexual assault; Psychometric; Culpability; Blame; Control; Responsibility 
Blame, Control, or Responsibility? Validation of Sexual Assault Culpability Measures

\section{Introduction}

\section{Overview}

Globally, one in five women will be subjected to sexual assault in their lifetime (García-Moreno, 2005; Rape Crisis UK, 2019). The scope of this problem highlights the importance of examining how sexual aggression towards women can be maintained on this scale, and why so many rapes go un-reported. Although there are many reasons why victims are reluctant to report rape to police, it has been suggested that a major reporting barrier is the woman's fear that police will question the veracity and credibility of her claims, or even blame her for their assault. Unfortunately, this concern appears to hold some truth, as a large evidence base suggests that victim blame is prevalent in rape cases, particularly when the victim knows the perpetrator (Gravelin et al., 2018; Persson \& Dhingra, 2021; Suarez \& Gadalla, 2010). This highlights both victim and perpetrator blame as highly relevant constructs in the context of researching sexual assault and rape attributions.

Much previous research has measured various aspects of victim and perpetrator blame, but as we have highlighted in some of our past research (e.g., Persson \& Dhingra, $2020 ; 2021)$, there has at times been a lack of clarity in the conceptualisation of victim blame. In other words, "victim blame" and "perpetrator blame" have been used in a rather broad sense, with considerable variation in the exact items used to measure these attributions. In our previous review of the literature (Persson \& Dhingra, 2020), we note that items used to index "victim blame" vary substantially. Some researchers have assessed blame, while others have assessed culpability, responsibility, guilt, and control. As such, these variations may reduce the reproducibility of research more generally in this area, and limit the degree to which 
findings can be compared across studies, as they may be indexing different attributions.

While there is mixed evidence as to the difference between some of these constructs (e.g., Gravelin et al., 2018; Richardson \& Campbell, 1980; Shaver \& Drown, 1986), our recent exploratory analyses (Persson \& Dhingra, 2021) indicated that women subjected to rape were attributed significantly more control, than blame, or responsibility. As such, there is an evident need for validated measures of these constructs, as this will contribute to a strengthening of the methodology of this field.

\section{The Current Report}

As part of our recent investigation into victim and perpetrator culpability in rape cases (Persson \& Dhingra, 2021), we drew on previous research in this area to devise victim and perpetrator culpability scales. These scales are intended to be used to measure victim and perpetrator culpability in response to varying situations of rape, for instance through the use of a vignette design.

Victim culpability was conceptualised as the degree to which participants implicated the victim in the assault, and perpetrator culpability as the degree to which participants implicated the perpetrator in the assault. Each culpability scale consisted of 12 items, and in line with the considerations above, as well as those advanced by Davies et al. (2006), initial items drew on blame $(n=4)$, responsibility $(n=3)$, and control $(n=5)$ as relevant constructs. Items of blame tapped into beliefs that the victim/perpetrator should be held accountable for the assault; items of responsibility tapped into beliefs that the victim/perpetrator's choices or actions contributed to the assault; and items of control tapped into beliefs that the victim/perpetrator had the power to influence or direct people's behaviour or the course of events. Some items were adapted from other research (Abrams et al., 2003; Ayala et al., 2018; Bieneck \& Krahe, 2011; Davies \& McCartney, 2003; Franklin \& Garza, 2018), and others were created following a comprehensive literature review (Persson \& Dhingra, 2020). 
The initial victim culpability scale consisted of 12 items, which asked participants to indicate their level of agreement with various statements about a woman depicted in a fictional scenario. Our OSF page (https://osf.io/92bq7/) provides six validated scenarios that can be used in conjunction with the scales. Each item is rated on a 7-point Likert-type scale (1 = "strongly disagree"; 2 = "disagree"; 3 = "somewhat disagree"; 4 = "neither agree nor disagree"; 5 = "somewhat agree"; 6 = "agree"; 7 = "strongly agree"), with a high score indicated that participants implicated the woman more in the assault. The degree to which participants implicated the perpetrator was measured using the same items as for victim culpability (initially consisting of 12 items) but mentions of 'the woman' in the fictitious scenario were replaced with 'the man'. Participants indicated their level of agreement on the same 7-point Likert-type scale (1 = "strongly disagree"; 2 = "disagree"; 3 = "somewhat disagree"; 4 = "neither agree nor disagree"; 5 = "somewhat agree"; 6 = "agree"; 7 = "strongly agree"). A high score indicated that participants implicated the man more in the assault. As our past research indicates a less than perfect correlation between victim and perpetrator culpability (Persson \& Dhingra, 2021), we suggest that there is a utility in measuring these constructs separately, rather than as one combined measure. The scale items, as well as their relation to the underlying constructs can be found in Table 1. 
Table 1. All Items Tested in the Intial Models for Victim and Perpetrator Culpability

\begin{tabular}{|c|c|c|}
\hline \multicolumn{3}{|c|}{ Victim Culpability $(n=12)$} \\
\hline Factor & Code & Item \\
\hline Blame & $V B 1^{\wedge}$ & The woman in this story cannot be blamed for what happened \\
\hline Blame & $V B 3$ & This incident was the woman's fault \\
\hline Blame & $V B 6$ & The woman's behaviour was to blame for what the man did. \\
\hline Blame & $V B 10$ & The woman is to blame for these circumstances. \\
\hline Responsibility & $V B 8^{\wedge}$ & The woman is not responsible for these circumstances. \\
\hline Responsibility & $V B 11$ & The woman is responsible for what happened. \\
\hline Responsibility & $V B 12$ & The woman is the cause of what happened. \\
\hline Control & $V B 2$ & The woman in this story could have avoided the incident. \\
\hline Control & $V B 4$ & The woman had control over the situation. \\
\hline Control & $V B 5 * \Lambda$ & $\begin{array}{l}\text { The woman cannot be blamed for what happened to her. She } \\
\text { was just in the wrong place at the wrong time. }\end{array}$ \\
\hline Control & $V B 7$ & $\begin{array}{l}\text { The woman could have acted differently to avoid this } \\
\text { outcome. }\end{array}$ \\
\hline Control & $V B 9$ & The situation was influenced by the woman. \\
\hline \multicolumn{3}{|c|}{ Perpetrator Culpability $(n=12)$} \\
\hline Factor & Code & Item \\
\hline Blame & $P B 1^{\wedge}$ & The man in this story cannot be blamed for what happened \\
\hline Blame & $P B 3$ & This incident was the man's fault \\
\hline Blame & PB6 & The man's behaviour was to blame for what the man did. \\
\hline Blame & PB10 & The man is to blame for these circumstances. \\
\hline Responsibility & $P B 8^{\wedge}$ & The man is not responsible for these circumstances. \\
\hline Responsibility & $V B 11$ & The man is responsible for what happened. \\
\hline Responsibility & PB12 & The man is the cause of what happened. \\
\hline Control & $P B 2 *$ & The man in this story could have avoided the incident. \\
\hline Control & $P B 4 *$ & The man had control over the situation. \\
\hline Control & $P B 5^{\wedge}$ & $\begin{array}{l}\text { The man cannot be blamed for what happened to her. She } \\
\text { was just in the wrong place at the wrong time. }\end{array}$ \\
\hline Control & $V B 7$ & The man could have acted differently to avoid this outcome. \\
\hline Control & $V B 9$ & The situation was influenced by the man. \\
\hline
\end{tabular}

*Dropped from the final model ^ $\wedge$ Reverse-scored 
Regarding reliability and structure, we hypothesised that:

1) CFA will support the proposed three-factor (blame, control, and responsibility) structure of the two culpability scales;

2) Both culpability scales, and their subscales, will display adequate or better internal consistency.

\section{Methods}

\section{Participants}

Community participants were recruited through Prolific (Prolific.co) as part of a larger study into the impact of victim-perpetrator relationship on attributions in rape cases. In determining sample size, we drew on numerous authors' considerations for sample size in factor analyses, which included 5-10 participants per parameter (Schreiber et al., 2010), between 150-180 overall (Mundfrom et al., 2005), 190 overall (Wolf et al., 2013), and 200 overall (Epskamp, 2020). Under each of these conditions, the current sample size is satisfactory. Two-hundred and fifty-five participants were included in the analysis. Participants were all UK residents with a mean age of $34.77(S D=10.22$, median $=33$, min $=18, \max =67)$. The sample included $75 \%$ women $(n=190), 24.7 \%$ men $(n=63)$, and $0.3 \%$ non-binary $(n=2)$ people. The vast majority were heterosexual $(85 \%)$, and a minority identified as bisexual (10\%), gay (4\%), or another sexuality not listed (1\%). In terms of ethnicity, participants were White (92\%), Asian (3.1\%), Black British (2.4\%), and of Other or Mixed Ethnicity (2.5\%).

\section{Ethical Approval}


The study received ethical approval from the local ethics co-ordinator at Leeds Beckett University and was conducted in accordance with the British Psychological Society's (BPS) Code of Ethics (2018).

\section{Data Transparency Statement}

All materials (including the vignettes developed and validated in conjunction with the scales) that were developed for this article can be found in repositories on the Open Science Framework (https://osf.io/92bq7/) as part of the larger, previously published research project (Persson \& Dhingra, 2020), where this dataset is from. In addition, we also include links to repositories where the full datasets will be posted once all analyses are complete (https://osf.io/92bq7/), and the code that was used for the analysis.

\section{General Results}

\section{Analysis strategy}

Two models of the latent structure of both victim and perpetrator culpability were specified and tested using CFA. Model 1 is a correlated first-order three-factor model (i.e., blame, responsibility, and control). Model 2 is a one-factor model where all items load on a single culpability latent variable. The robust maximum likelihood estimation (MLR: Yuan \& Bentler, 1997) was used due to the non-normality of our data (as determined through examining histograms). It is generally expected that data on victim and perpetrator blame demonstrate non-normality, as levels of victim blame tend to be low, and levels of perpetrator blame tend to be high (Persson \& Dhingra, 2020; 2021), and this was the case with the current dataset. Further details on the spread of the data can be found in Persson \& Dhingra (2021).

The CFA analyses were performed in R (Version 3.52), using the lavaan (Rossseel, 2021) package for CFA and SEM, and standard guidelines for determining model fit were followed (see Bollen, 1989; Hu \& Bentler, 1999). Acceptable model fit was indicated by a 
non-significant chi-square $(\chi 2)$ result; Comparative Fit Index (CFI) and Tucker-Lewis Index (TLI) values of $\geq 0.90$ and $\geq 0.95$ reflecting acceptable and excellent model fit, respectively; and Root Mean Square Error of Approximation (RMSEA) values, with 90\% confidence intervals of $\leq 0.08$ and $\leq 0.06$ reflecting acceptable and excellent model fit, respectively. The $\chi 2$ statistic has been noted to be strongly associated with sample size, and, as such, good models tend to be over-rejected (Schermelleh-Engel et al., 2003; Tanaka, 1987). Therefore, in line with Tanaka (1987), models were not rejected simply on the basis of a significant $\chi^{2}$ result. Furthermore, the Bayesian information criterion (BIC) and Akaike information criterion (AIC) were used to evaluate alternative models (i.e., the 1-factor model compared to the the 3-factor model), where comparatively smaller values indicate better model fit. The models specified and tested in this research allowed items to load only onto a single factor, with uncorrelated measurement error terms, as suggested in previous research (Bollen, 1989). There were no missing data.

\section{Results for Victim Culpability}

Due to a low factor loading $(\beta=0.32), V B 5$ was dropped from the analyses, resulting in an 11-item scale. The model fit results for the models of Victim Culpability (using the 11 items with acceptable levels of loading) are reported in Table 1. This table also compares fit indices between the three-factor model (with the culpability sub-scales) and a one-factor model (full culpability construct). As can be seen, the CFI, TFI, RMSEA, and the SRMR all indicated a good level of model fit for both models, but all indices show improvement in the three-factor model (Table 1), which include the AIC and BIC indices. Although the chisquare is large in relation to the degree of freedom, and statistically significant, Tankaka (1987) states that a model should not be rejected on this basis, since large sample sizes amplify the power of the test. 
Table 1. Fit statistics for the CFA models of the Victim Culpability Scale

\begin{tabular}{|c|c|c|c|c|c|c|c|}
\hline Model & $\begin{array}{l}\text { Chi' }^{2} \\
(\text { df }), p\end{array}$ & CFI & TLI & $\begin{array}{l}\text { RMSEA } \\
(90 \% \mathrm{CI})\end{array}$ & SRMR & ssBIC & AIC \\
\hline $\begin{array}{l}\text { Victim } \\
\text { culpability } \\
\text { (3-factor) }\end{array}$ & $\begin{array}{l}62.50 \\
(41, p=0.02)\end{array}$ & 0.95 & 0.93 & $\begin{array}{l}0.05 \\
(0.03,0.05)\end{array}$ & 0.07 & 5277.43 & 5268.05 \\
\hline $\begin{array}{l}\text { Victim } \\
\text { culpability } \\
\text { (1-factor) }\end{array}$ & $\begin{array}{l}88.78 \\
44,(p<.001)\end{array}$ & 0.89 & 0.86 & $\begin{array}{l}0.06 \\
(.05,0.07)\end{array}$ & 0.07 & 5342.61 & 5334.46 \\
\hline
\end{tabular}

Note. CFA $=$ comparative fit index; TLI $=$ Tucker-Lewis index; RMSEA $=$ root mean square error of approximation; $\mathrm{SRMR}=$ standardised square root mean residual; $\mathrm{AIC}=\mathrm{Akaike}$ information criterion; ssBIC $=$ sample size adjusted Bayesian information criterion.

The adequacy of this three-factor model can also be determined in relation to its parameter estimates. The standardised factor loadings for the final, three-factor model of Victim Culpability are presented in Table 2.

Table 2. Unstandardised and standardized factor loadings (and standard errors) for the threefactor model of Victim Culpability.

\begin{tabular}{l|l|l|l|l}
\hline Latent Variable & $\begin{array}{l}\text { Observed } \\
\text { variable }\end{array}$ & $\mathbf{B}$ & $\boldsymbol{\beta}$ & SE \\
\hline Blame & $V B 1$ & $1.00^{\wedge}$ & $0.46^{* *}$ & - \\
& $V B 3$ & 0.47 & $0.73^{* *}$ & 0.15 \\
$V B 6$ & 0.74 & $0.83^{* *}$ & 0.16 \\
Responsibility & $V B 10$ & 0.712 & $0.70^{* *}$ & 0.22 \\
Control & $V B 8$ & $1.00^{\wedge}$ & $0.42^{* *}$ & - \\
& $V B 11$ & 0.76 & $0.86^{* *}$ & 0.13 \\
& $V B 12$ & 0.82 & $0.71^{* *}$ & 0.15 \\
& $V B 2$ & $1.00^{\wedge}$ & $0.82^{* *}$ & - \\
& $V B 4$ & 0.49 & $0.59^{* *}$ & 0.10 \\
& $V B 5^{*}$ & 0.48 & $0.32^{* *}$ & 0.11 \\
& $V B 7$ & 1.09 & $0.80^{* *}$ & 0.19 \\
& $V B 9$ & 0.42 & $0.59 * *$ & 0.07 \\
\hline
\end{tabular}

Note. ${ }^{*}$ Dropped from later analyses due to low loadings; ${ }^{\wedge}$ Loading fixed to 1.

** Statistically significant $(p<.001)$. 
All items loaded positively, and statistically significantly onto their respective latent factor, and all factor loadings were of a robust magnitude $(>0.40)$ with the exception of item $\operatorname{VB5}(\beta=0.32)$. This suggests that this item is a poor indicator of the 'control' latent factor, and was therefore removed from the scale, and the full model results are without this item included. The factor loadings are displayed in Figure 1.

Figure 1. Plot Illustrating Latent and Observed Variables for Victim Culpability

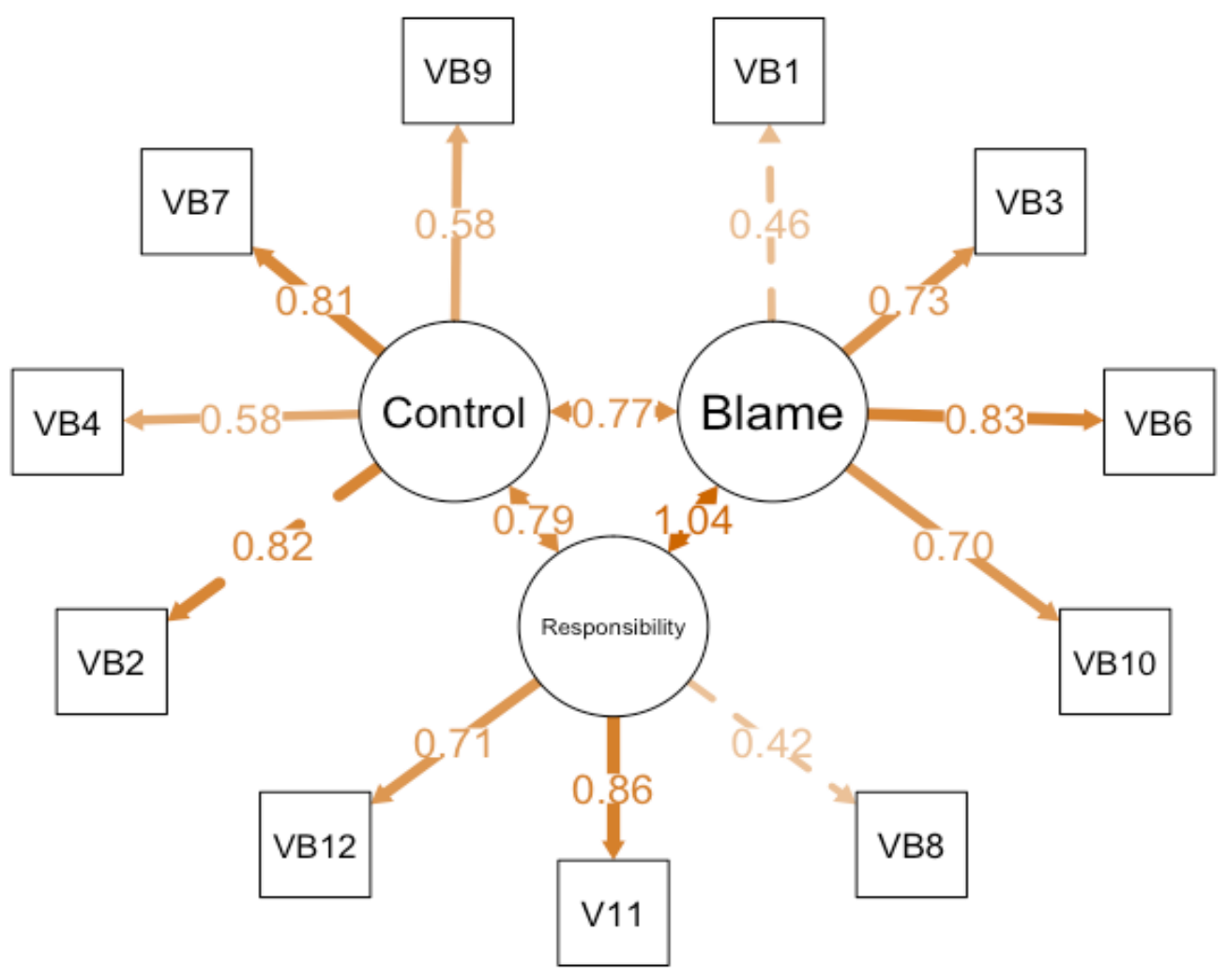

Note. All paths significant at $p<.001$. Paths between observed and latent variables displaying standardised variables. Covariances between latent constructs displaying unstandardised variables. 
Based on the standardised covariance estimates, the three factors were all moderately and positively associated with each other (blame/responsibility: $r=0.30, p=0.001$; blame/control: $\mathrm{r}=0.45, \mathrm{p}<0.001$; responsibility/control: $\mathrm{r}=0.46, \mathrm{p}<0.001)$. This indicates a reasonable degree of discrimination between factors. Cronbach's alpha indicated that the blame $(\alpha=0.72)$, control $(\alpha=0.78)$, and responsibility $(\alpha=0.67)$ items mostly possessed acceptable internal reliability. Smaller alpha levels are to be expected when assessing fewer items (as is the case for blame, control, and responsibility), and is not necessarily indicative of low reliability (Stjtsma, 2009; Taber, 2018). As the overall, 11-item scale, had excellent reliability ( $\alpha=0.89$ ), we conclude that the overall reliability of our items is good. Taken together, these results support the factorial validity and internal reliability of the Victim Culpability Scale within the current sample.

\section{Results for Perpetrator Culpability}

Due to low levels of loadings ( $\beta=0.23$ and $\beta=0.29$, respectively), $P B 2$ and $P B 4$ were dropped from the analyses, and CFA model results (Table 3) do not include these items. The model fit results (10 items) are reported in full in Table 3 and, as can be seen, both models were found to be an adequate representation of the data. 
Table 3. Fit statistics for the CFA models of the Perpetrator Culpability Scale

\begin{tabular}{llllllll}
\hline Model & $\begin{array}{l}\mathbf{C h i}^{2} \\
(\mathbf{d f})\end{array}$ & CFI & TLI & $\begin{array}{l}\text { RMSEA } \\
(\mathbf{9 0 \%} \mathbf{C I})\end{array}$ & SRMR & SsBIC & AIC \\
\hline $\begin{array}{l}\text { Perpetrator } \\
\begin{array}{l}\text { culpability (3- } \\
\text { factor) }\end{array}\end{array}$ & $\begin{array}{l}35.51(32) \\
p=0.31\end{array}$ & 0.99 & 0.98 & 0.02 & 0.07 & 3312.16 & 3303.66 \\
$\begin{array}{l}\text { Perpetrator } \\
\begin{array}{l}\text { culpability (1- } \\
\text { factor) }\end{array}\end{array}$ & $\begin{array}{l}37.95(35), \\
p=0.34\end{array}$ & 0.99 & 0.98 & 0.02 & 0.04 & 3308.39 & 3300.97 \\
\hline
\end{tabular}

Note. CFA $=$ comparative fit index; TLI $=$ Tucker-Lewis index; RMSEA $=$ root mean square error of approximation; $\mathrm{SRMR}=$ standardised square root mean residual; $\mathrm{AIC}=$ Akaike information criterion; ssBIC = sample size adjusted Bayesian information criterion.

As can be seen in Table 3, the Chi-Square, CFI, TFI, RMSEA, and the SRMR all indicated a good level of model fit, using the robust estimator. This table also compares fit indices between the three-factor model (with the culpability sub-scales) and a one-factor model (full culpability construct). This comparison, as well as the AIC and BIC, illustrate largely similar fits for the two models. As Model 1 provided similar fit to Model 2, and the ssBIC value did not exceed 10, Model 1 was preferred on the grounds of theoretical parsimony.

The standardised factor loadings for the final, three-factor model of Perpetrator Culpability are presented in Table 4. 
Table 4. Unstandardised and Standardized Factor Loadings (and Standard Errors) for the One-Factor Model of Perpetrator Culpability.

\begin{tabular}{lllll}
\hline Latent Variable & $\begin{array}{l}\text { Observed } \\
\text { variable }\end{array}$ & & $\boldsymbol{\beta}$ & SE \\
\hline Blame & $P B 1$ & $1.00^{\wedge}$ & $0.41^{* *}$ & - \\
& $P B 3$ & 1.24 & $0.62^{* *}$ & 0.18 \\
& $P B 6$ & 1.06 & $0.71^{* *}$ & 0.10 \\
& $P B 10$ & 1.11 & $0.76^{* *}$ & 0.09 \\
Responsibility & & & & \\
& $P B 8$ & $1.00^{\wedge}$ & $0.55^{* *}$ & - \\
& $P B 11$ & 1.08 & $0.92^{* *}$ & 0.16 \\
& $P B 12$ & 1.02 & $0.84^{* *}$ & 0.15 \\
Control & $P B 2^{*}$ & $1^{\wedge}$ & $0.23^{* *}$ & - \\
& $P B 4^{*}$ & 1.69 & $0.30^{* *}$ & 0.61 \\
& $P B 5$ & $1^{\wedge}$ & $0.67^{* *}$ & - \\
& $P B 7$ & 0.52 & $0.42^{* *}$ & 0.18 \\
& $P B 9$ & 1.05 & $0.65^{* *}$ & 0.16 \\
\hline
\end{tabular}

Note. *Dropped from later analyses due to low loadings; ^Loading fixed to 1. $* *$ Statistically significant $(p<0.01)$.

All items loaded positively, and statistically significantly onto their respective latent factor, and all factor loadings were of a robust magnitude $(>0.40)$ with the exception of items $P B 2(\beta=0.23)$, and $P B 4(\beta=0.29)$. This suggests that these items are a poor indicators of the 'control' latent factor, and were therefore removed from the scale, and then model results are without these items included. The factor loadings are displayed in Figure 2. 
Figure 2. Figure 1. Plot Illustrating Latent and Observed Variables for Perpetrator Culpability

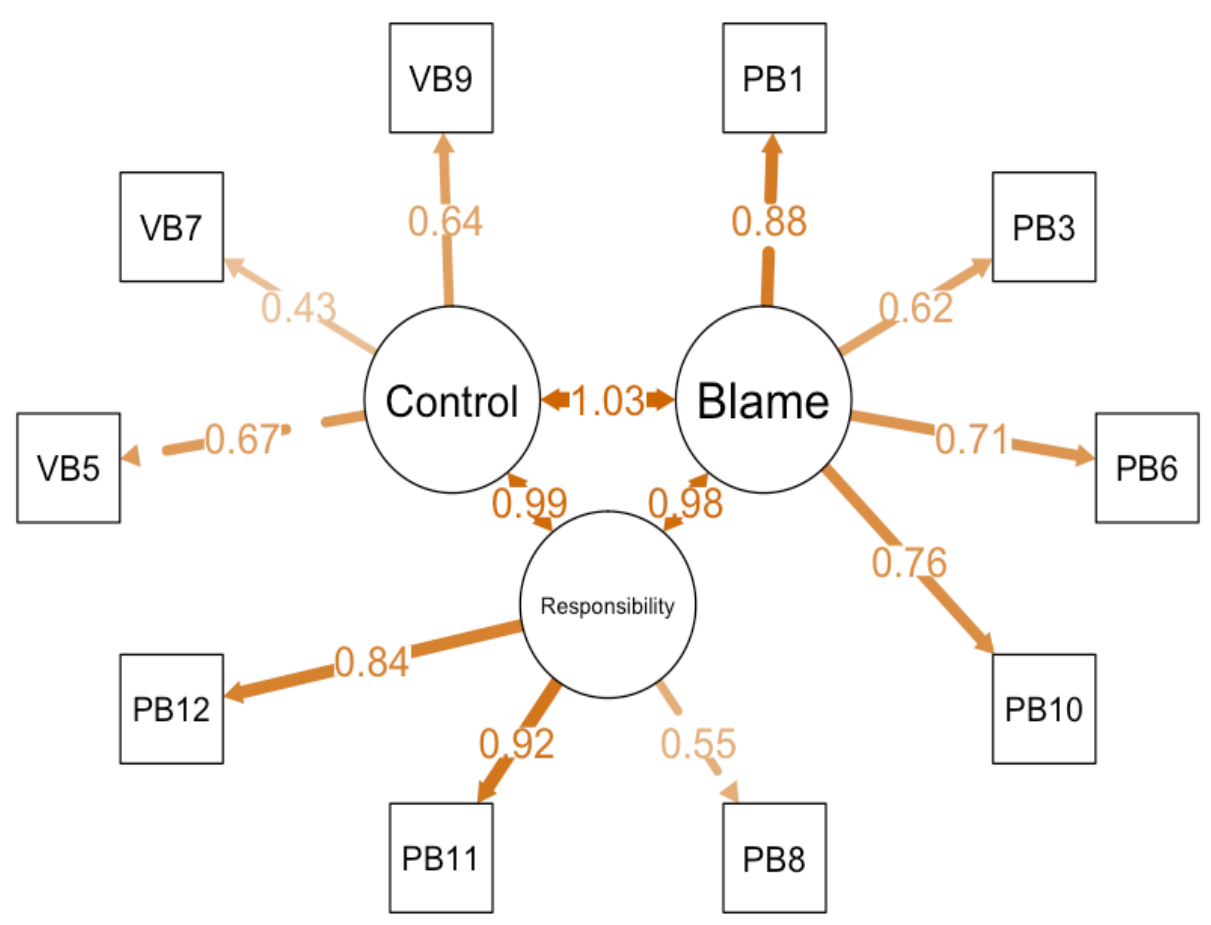

Note. All paths from the observed to latent variables are significant at $p<.01$. Latent paths are significant at $p<.05$, except blame/control. Paths between observed and latent variables displaying standardised variables. Covariances between latent constructs displaying unstandardised variables.

Most of the three factors were moderately and positively associated with each other (blame/responsibility: $r=0.17, p=0.03$; responsibility/control: $r=0.174, p=0.03$ ). The factors blame/control were not correlated: $r=0.18, p=.07)$. This indicates a reasonable degree of discrimination between factors. Cronbach's alpha indicated that the blame $(\alpha=0.81)$, control $(\alpha=0.61)$, and responsibility $(\alpha=0.80)$ items possessed acceptable internal reliability. As with the victim culpability constructs, smaller alpha levels are generally expected with fewer items, and is not strictly indicative of low reliability (Stjtsma, 2009; Taber, 2018). The 
overall, 10 -item, perpetrator culpability scale had excellent reliability $(\alpha=0.91)$, and we therefore conclude that overall item reliability is good. Taken together, these results support the factorial validity and internal reliability of the Perpetrator Culpability Scale within the current sample. Table 5 presents the final items for the victim and perpetrator culpability scales, and their relationships to the latent constructs.

Table 5. Final Items for Victim and Perpetrator Culpability models

\begin{tabular}{|c|c|c|}
\hline \multicolumn{3}{|c|}{ Victim Culpability $(n=11)$} \\
\hline Blame & $\mathrm{VB} 1^{\wedge}$ & The woman in this story cannot be blamed for what happened \\
\hline Blame & VB3 & This incident was the woman's fault \\
\hline Blame & VB6 & The woman's behaviour was to blame for what the man did. \\
\hline Blame & VB10 & The woman is to blame for these circumstances. \\
\hline Responsibility & $\mathrm{VB} 8^{\wedge}$ & The woman is not responsible for these circumstances. \\
\hline Responsibility & VB11 & The woman is responsible for what happened. \\
\hline Responsibility & VB12 & The woman is the cause of what happened. \\
\hline Control & VB2 & The woman in this story could have avoided the incident. \\
\hline Control & VB4 & The woman had control over the situation. \\
\hline Control & VB7 & $\begin{array}{l}\text { The woman could have acted differently to avoid this } \\
\text { outcome. }\end{array}$ \\
\hline Control & VB9 & The situation was influenced by the woman. \\
\hline \multicolumn{3}{|c|}{ Perpetrator Culpability $(n=10)$} \\
\hline Blame & $\mathrm{PB} 1^{\wedge}$ & The man in this story cannot be blamed for what happened \\
\hline Blame & PB3 & This incident was the man's fault \\
\hline Blame & PB6 & The man's behaviour was to blame for what the man did. \\
\hline Blame & PB10 & The man is to blame for these circumstances. \\
\hline Responsibility & $\mathrm{PB}^{\wedge} \wedge$ & The man is not responsible for these circumstances. \\
\hline Responsibility & VB11 & The man is responsible for what happened. \\
\hline Responsibility & PB12 & The man is the cause of what happened. \\
\hline Control & $\mathrm{PB}^{\wedge}$ & $\begin{array}{l}\text { The man cannot be blamed for what happened to her. She } \\
\text { was just in the wrong place at the wrong time. }\end{array}$ \\
\hline Control & VB7 & The man could have acted differently to avoid this outcome. \\
\hline Control & VB9 & The situation was influenced by the man. \\
\hline
\end{tabular}

AReverse scored 


\section{Discussion}

The present report tested the validity of two three-factor scales to measure victim and perpetrator culpability in the context of sexual assault on a sample of 255 community participants. We dropped one item for the victim culpability (VC) scale, resulting in an 11item scale, with four items measuring victim blame, three items measuring victim responsibility, and four items measuring perceived victim control. We dropped two items for the perpetrator culpability (PC) scale, resulting in a 10-item scale, with four items measuring perpetrator blame, three items measuring perpetrator responsibility, and three items measuring perceived perpetrator control. According to most fit-indices, both the one factor models (culpability) and three-factor models (with domains of blame, responsibility, and control) for VC and PC provided a good fit to our data, indicating that future researchers can use both participants' total culpability score, as well as their individual domain scores in the context of attributions in rape cases. For researchers who are interested in using these scales in conjunction with various victim-perpetrator relationship scenarios, our OSF page (https://osf.io/92bq7/) provides six validated vignettes that can be used to this purpose. Future researchers may also wish to consider whether there are further relevant underlying domains within culpability attributions, and whether adding different items may be relevant for either of the two constructs. Another relevant extension would be the validation of these scales in other countries and contexts, as the current sample is drawn exclusively from the UK.

Through devising and validating of measures for victim and perpetrator attributions, the current report fills a considerable gap in past literature, and contributes more generally to improved methodologies in this research area. As noted by other researchers (e.g., Grubb \& Turner, 2012) as well as in some of our previous research (Persson \& Dhingra, 2020; 2021), methodological variations in past studies have produced conflicting results on blame 
attributions in rape cases, and limited the degree to which findings can have consistent applications within policy and practice. Reproducibility is a concern for the Social Sciences more generally, and sexual assault attribution research is no exception. As such, the need for researchers to use reliable material and validated measurement tools is evident, and we also recommend that researchers make the samples and materials used for this validation openly available, once all analyses have been conducted. Open Science and transparent research practices may therefore have positive implications for the research field overall. Conclusively, this paper broadly seeks to contribute to central tenets of paradigm-driven research (Nosek, Spies, \& Motyl, 2012), i.e., where research methodologies are continually updated and improved to strengthen the research field more generally, particularly in the context of laying a foundation for future research in the area.

\section{References}

Abrams, D., Viki, G. T., Masser, B., \& Bohner, G. (2003). Perceptions of stranger and acquaintance rape: The role of benevolent and hostile sexism in victim blame and rape proclivity. Journal of Personality and Social Psychology, 84(1), 111-125. $10.1037 / 0022-3514.84 .1 .111$

Ayala, E. E., Kotary, B., \& Hetz, M. (2018). Blame attributions of victims and perpetrators: Effects of victim gender, perpetrator gender, and relationship. Journal of Interpersonal Violence, 33(1), 94-116. https://doi.org/10.1177/0886260515599160

Bollen, K.(1989). Structural equations with latent variables. New York: John Wiley, 612-21.

British Psychological Society. (2018). Code of ethics and conduct. https://www.bps.org.uk/news-and-policy/bps-code-ethics-and-conduct 
Davies, M., \& McCartney, S. (2003). Effects of gender and sexuality on judgements of victim blame and rape myth acceptance in a depicted male rape. Community and Applied Social Psychology, 13(5), 391-398. https://doi.org/10.1002/casp.741

Epskamp, S. (2020). Confirmatory Factor Analysis: Week Two - Sample Size. Retrieved from: http://sachaepskamp.com/files/SEM2020/SEM1Week2_2020_sampleSize.pdf

Epskamp, S. (2019). semPlot. R package (1.1.2) [Computer software]. https://cran.rproject.org/web/packages/semPlot/index.html

Franklin, C. A., \& Garza, A. D. (2018). Sexual Assault Disclosure: The Effect of Victim Race and Perpetrator Type on Empathy, Culpability, and Service Referral for Survivors in a Hypothetical Scenario. Journal of Interpersonal Violence. https://doi.org/10.1177/0886260518759656

García-Moreno, C. (2005). WHO multi-country study on women's health and domestic violence against women: Initial results on prevalence, health outcomes and women's responses. Retrieved from http://www.who.int/gender/violence/who_multicountry_study/en

Gravelin, C. R., Biernat, M., \& Bucher, C. E. (2018). Blaming the Victim of Acquaintance Rape: Individual, Situational, and Sociocultural Factors. Frontiers in Psychology, 9, 2422. https://doi.org/10.3389/fpsyg.2018.02422

Grubb, A., \& Turner, E. (2012). Attribution of blame in rape cases: A review of the impact of rape myth acceptance, gender role conformity and substance use on victim blaming. Journal of Interpersonal Violence, 17(5), 443-452.

https://doi.org/10.1016/j.avb.2012.06.002

Hu, L. T., \& Bentler, P. M. (1999). Cutoff criteria for fit indexes in covariance structure analysis: Conventional criteria versus new alternatives. Structural Equation 
Modeling: a Multidisciplinary Journal, 6(1), 1-55.

https://doi.org/10.1080/10705519909540118

Mundfrom, D. J., Shaw, D. G., \& Ke, T. L. (2005). Minimum Sample Size

Recommendations for Conducting Factor Analyses. International Journal of Testing, 5(2), 159-168. https://doi.org/10.1207/s15327574ijt0502 4

Nosek, B. A., Spies, J. R., \& Motyl, M. (2012). Scientific Utopia: II. Restructuring Incentives and Practices to Promote Truth Over Publishability. Perspectives on Psychological Science, 7(6), 615-631. https://doi.org/10.1177/1745691612459058

Persson, S., \& Dhingra, K. (2020). Attributions of Blame in Stranger and Acquaintance Rape: A Multilevel Meta-Analysis and Systematic Review. Trauma, Violence, \& Abuse. https://doi.org/10.1177/1524838020977146

Persson, S., \& Dhingra, K. (2021). Moderating Factors in Culpability Ratings and Rape Proclivity in Stranger and Acquaintance Rape: Validation of Rape Vignettes in a Community Sample. Journal of Interpersonal Violence. https://doi.org/10.1177/0886260521991294

Prolific (2021). Prolific (05.20). https://www.prolific.co

R Foundation for Statistical Computing. (2020). R Core Team (3.62) [Computer software]. https://www.R-project.org/

Rape Crisis UK. (2019). Statistics-Sexual Violence I Rape Crisis England \& Wales. http://rapecrisis.org.uk/get-informed/about-sexual-violence/statistics-sexual-violence/

Richardson, D. C., \& Campbell, J. L. (1980). Alcohol and Wife Abuse: The Effect of Alcohol on Attributions of Blame for Wife Abuse. Personality and Social Psychology Bulletin, 6(1), 51-56. https://doi.org/10.1177/014616728061007

Rosseel, Y. (2021). lavaan. R package (0.6-8) [Computer software]. https://cran.rproject.org/web/packages/lavaan/lavaan.pdf 
Schermelleh-Engel, K., Moosbrugger, H., \& Müller, H. (2003). Evaluating the fit of structural equation models: Tests of significance and descriptive goodness-of-fit measures. Methods of psychological research online, 8(2), 23-74.

Shaver, K. G., \& Drown, D. (1986). On causality, responsibility, and self-blame: A theoretical note. Journal of Personality and Social Psychology, 50(4), 697-702. doi:10.1037/0022-3514.50.4.697

Suarez, E., \& Gadalla, T. M. (2010). Stop Blaming the Victim: A Meta-Analysis on Rape Myths. Journal of Interpersonal Violence, 25(11), 2010-2035. https://doi.org/10.1177/0886260509354503

Tanaka, J. S. (1987). " How big is big enough?": Sample size and goodness of fit in structural equation models with latent variables. Child Development, 134-146. https://doi.org/10.2307/1130296

Wolf, E. J., Harrington, K. M., Clark, S. L., \& Miller, M. W. (2013). Sample Size Requirements for Structural Equation Models: An Evaluation of Power, Bias, and Solution Propriety. Educational and Psychological Measurement, 76(6), 913-934. https://doi.org/10.1177/0013164413495237

Yuan, K.-H., \& Bentler, P. M. (1998). 9. Structural Equation Modeling with Robust Covariances. Sociological Methodology, 28(1), 363-396. 